\title{
Pricing Strategy of Electric Power Data Credit Product Based on Customer Value
}

\author{
Zhimin Wang $\mathbb{D}$ and Di Wang \\ State Grid Energy Research Institute Co., LTD, Beijing 102211, China \\ Correspondence should be addressed to Zhimin Wang; wangzhimin@sgeri.sgcc.com.cn
}

Received 25 October 2021; Accepted 23 December 2021; Published 3 March 2022

Academic Editor: Daqing Gong

Copyright ( 2022 Zhimin Wang and Di Wang. This is an open access article distributed under the Creative Commons Attribution License, which permits unrestricted use, distribution, and reproduction in any medium, provided the original work is properly cited.

\begin{abstract}
With the improvement of the intelligence level of the power network and the gradual improvement of the information and communication of the power system, the application of power big data to the corporate credit market is not only an important supplement to the national social credit system but also an important strategic goal for the State Grid to expand profitability. This paper constructs a benefit evaluation model for power data credit investigation products based on the utility of the products that financial institutions experience when they purchase and use financial risk control products. Based on the theory of customer value, comprehensively considering the characteristics of power credit reporting products, and taking profit maximization as the corporate goal, the pricing of a single power credit reporting product is studied, and the method is verified using example products. This article gives the pricing strategy of power credit investigation, which can be used as a reference for enterprises to further develop market strategies.
\end{abstract}

\section{Introduction}

With the improvement of the intelligent level of the power network and the gradual improvement of the information communication of the power system, more power data can be obtained, including the basic information of users, the monitoring data of power line equipment, the information of power generation, transmission, distribution, and consumption in the process of production and marketing, as well as the voltage and current in the power network. These data have the characteristics of high credibility, strong timeliness, good continuity, good integrity, and wide coverage. By the analysis of power data, the integration of power grid data and field data can be strengthened, which not only provides support for urban management, energy control, and environmental control but also better reflects the credit level of an enterprise. It can track the production and operation situation and trends of enterprises in real-time and control the risks of enterprises. The application of power big data to the enterprise credit market is not only an important supplement to the national social credit system but also one of the important measures for the strategic goal of expanding the profitability of the State Grid.

Because of the strong originality and nonrepetitive characteristics of power big data credit products and the short time of application in the field of enterprise credit, it is difficult to accurately evaluate the credibility and customer value of products, resulting in the lack of reasonable pricing strategies for products, which directly affects the market promotion of power big data credit products. Product price is the basis of product sales. It is an important way for enterprises to make profits, and it is also the embodiment of enterprise development strategy. Therefore, a reasonable product pricing strategy will help enterprises to speed up market response, reduce repetitive work and resource consumption, improve the performance of power data credit products in the credit product market, and promote the smooth realization of the profit target of enterprises.

In the White Paper on [1] published by China Information and Communication Research Institute (2016), it is clearly pointed out that the difficulty of pricing data products is one of the main problems facing big data transactions in 
China. Wu [2] pointed out that the difficulty in pricing data products is that the current fee standard for big data transactions in China is relatively rough. On the one hand, the credit information center has not yet given the accounting process of charging the benchmark service fee according to the number of credit reports. On the other hand, the fee adjustment coefficient only takes into account the two indicators of data contribution and data query, which is one-sided for evaluating the quality of credit data and is not enough to fully distinguish between high-quality and low-quality access agencies. On the basis of maintaining the existing credit data pricing formula, $\mathrm{Wu}$ further refines the benchmark service fee by combining the concept of quality cost, adopts the internationally accepted data quality evaluation index, establishes a new credit data quality evaluation system, defines different indicators, and designs the adjustment coefficient using the actuarial reward and punishment system.

Koski [3] found that the pricing of geographic information data in the public sector is closely related to the sales growth of enterprises by the study of public geographic information pricing schemes implemented in different countries. The marginal cost pricing of geographic information has made a great contribution to the sales growth of small and medium-sized enterprises, however, it has no significant impact on the growth of sales of large companies. Olejnik et al. [4] analyzed the impact of the advertiser's purpose on the value of the user's personal data and found that the price of the user's private web browsing data depends on the user's browsing records, especially the access data with content value. Zhang et al. [5] believe that the main impact of data asset value includes data asset cost and application. Based on this, the value evaluation model of data assets is constructed.

Koutris et al. [6] proposed a framework for pricing data on the internet, "query-based pricing", which allows the price of any query to be automatically derived. Lin et al. [7] proposed a no-arbitrage pricing function for general data query by comparing various pricing schemes on the premise of protecting the seller's income.

Riederer et al. [8] proposed a mechanism called "transactional" privacy, which is applied to the transaction of the personal information of users. Users decide how their personal information is published and sold while obtaining compensation and ensuring the interests of all parties in the transaction by the authenticity and efficiency of an unlimited supply auction. Dandekar et al. [9] studied the private data market. In this paper, we pay attention to the problem of personal privacy data auction in the private data market and design a real, personal, rational, proportional purchase auction mechanism under the fixed budget constraints of analysts. Li et al. [10] noted the value of personal privacy data and the compensation of data owners. Rosenthal [11] argues that the individual cost of privacy inevitably depends on some function of the different privacy parameters of the overall mechanism. Ghosh et al. [12] defined the concept of private data auction and proposed a multiunit procurement auction mechanism for private data. Jentzsch [13] proves that the RVA auction mechanism cannot obtain the value of private sensitive data products.
On the basis of analyzing and summarizing the concept and characteristics of big data products, Lili et al. [14] reviewed the research results on big data product pricing at home and abroad and summarized the pricing problems of big data products from three perspectives: the difficulties, influencing factors, models, and strategies of big data product pricing. On this basis, this paper puts forward some suggestions and ideas on the pricing of big data products from four perspectives of life cycle, quality, circulation process, and use mode of big data products, which will help the research and practice development of big data product pricing. Li [15] constructed the pricing model of telecom information products based on customer value. Taking the interests of enterprises as the goal and customer value as the constraint condition, the optimal price is obtained, and the function relationship between price and utility is established to study the pricing of cell phone newspaper. Liu [16] proposed a book pricing method based on customer perceived value, which takes customer perceived value as the core and uses conjoint analysis to comprehensively explore customer preferences for perceived value elements. According to the difference of customer perceived value, this paper uses the cluster analysis method to subdivide customers on the basis of the joint analysis of market segmentation, obtains the relationship and model between the customer perceived value and book price, uses a value map to analyze the customer perceived value and price positioning of competitors, combines the elements of consumer perceived value to analyze the cost and profit of book publishing, and sets the price of books. Fosu [17] analyzed the application of credit information in bank loans.

The application of big data in the field of enterprise credit reporting has the characteristics of uncertainty, scarcity, and diversity, and the product pricing is also vulnerable to the impact of data quality, data historical transaction price, and data utility. This paper discusses the pricing strategy of big data credit reporting products for electric power based on customer value.

\section{Customer Value Theory and Evaluation Index}

Customer value is a quantitative comparison between gains and losses (quality, price, profit, cost, total value, total cost, etc.), and it provides a standard reference for pricing work based on the evaluation of customer value. Customer value is a subjective judgment of customers, which is based on the environment and their own expectations in a specific situation. It is an overall evaluation of the perceived gains and losses from a product (or service). This definition combines expected value and perceived value and includes the following three meanings:

(1) Customer value is a subjective judgment of customers and cannot be evaluated objectively.

(2) Customer value is different and is influenced by many personal and situational factors, and the average value assessed by customers is used.

(3) Customer value is the overall evaluation of a product after the value felt by customers is offset by the loss they feel. 
Financial risk control service products include preloan antifraud, in-loan credit assistance, and postloan risk warning.

The power data credit investigation can monitor the operation status of the loan enterprise in real time for risk early warning, transmit the test results to the commercial bank, provide the real address of the enterprise and other information, and promptly notify the customer manager of the on-site investigation to prevent the formation of nonperforming loans, which reduces the monitoring cost of the bank and nonperforming loan risk.

According to the utility of financial institutions in purchasing and using financial risk control products, the product utility value evaluation table is formulated in Table 1 as follows:

\section{Benefit Evaluation Model of Electric Power Data Credit Product}

When users buy products, they will compare the utility of their purchase and use of products with the price they pay, i.e., the result of comparing their gains and losses. According to the general definition of customer value, this comparison result is customer value.

To simplify the problem, the assumptions made based on the previous theoretical research and the actual situation are as follows:

(1) The user has a different value for each attribute.

(2) The price utility coefficients of all users are the same.

(3) The relationship between price and utility is linear.

Based on the analysis of power credit products and model assumptions, the variables involved in the construction of the mathematical model are defined as follows:

$n$ : the number of attributes of the power credit product, which is a constant.

$u\left(g_{i}\right)$ : the user's preference for the first $i$ attributes $g_{i}$ utility value of performance.

$U$ : utility value of electric power credit products.

$u_{p}$ : the price utility of consumers to the price of electric power credit products.

(i) $\gamma$ : price utility coefficient, $\gamma<0$.

(ii) $\alpha$ : price utility base value.

(iii) $V$ : customer value of electric power credit products.

(iv) $p$ : the price of electricity credit products;

According to the above steps of customer value analysis, the process of establishing and solving the mathematical model is as follows:

3.1. Determine the Utility Value of the User. As electric power credit products have many attributes, users need to evaluate these attributes separately and make a comprehensive judgment, which is actually a multiattribute decisionmaking process.
When calculating the total utility of the product, the additive utility model is used, which is the mainstream model for studying utility and customer value, which is expressed as follows:

$$
U=\sum_{i=1}^{n} u\left(g_{i}\right)
$$

Among them, the products have $n$ product attributes, $g_{i}(i=1,2, \cdots, n)$ is the $\mathrm{i}^{\text {th }}$ attribute index of the product, and $u\left(g_{i}\right)$ is the utility value represented by the $\mathrm{i}^{\text {th }}$ attribute.

3.2. Determine the Price Utility of the User. Customer's price utility function $u_{p}$ and price $p$ is linear, which is expressed as follows:

$$
u_{p}=\alpha+\gamma p+\varepsilon
$$

$p$ is the price of electric power credit products. $\gamma$ Is the price utility coefficient, $\alpha$ is the price utility base value, and $\varepsilon$ is a random disturbance with normal distribution and zero expectation. As the price belongs to one of the user costs, in a practical sense, $\gamma<0$.

The price utility coefficient is the key bridge to connect the utility value with the price, and it is also an important aspect of customer perceived value, which is a kind of price perception.

3.3. Determine the Customer Value of Users. Customer value includes utility value and price utility relationship, which is expressed as follows:

$$
\begin{aligned}
V & =U+u_{p} \\
& =\sum_{i=1}^{n} u\left(g_{i}\right)+\alpha+\gamma p+\varepsilon .
\end{aligned}
$$

\section{Pricing Model of Electric Power Data Credit Product}

Considering the characteristics of electric power credit products, the pricing problem of single electric power credit product is studied with profit maximization as the enterprise goal. Based on the benefit evaluation model, the goal of State Grid Corporation is to maximize product revenue by setting product prices, and it needs to find a balance between user constraints and company interests, as shown in Figure 1.

According to the benefit evaluation model, the utility value of electric power credit products $U$ and the price utility of consumers to the price of electric power credit products $u_{p}$ can be obtained. The revenue of the State Grid Corporation is the total revenue minus the total cost, and the revenue is calculated by $\pi_{S G C}$ Express.

Based on the analysis of electric power credit products and the assumption of benefit evaluation model, the variables involved in the construction of mathematical model are defined according to the conceptual model of pricing, which are as follows: 
TABle 1: Product utility value assessment.

\begin{tabular}{|c|c|c|}
\hline & Evaluation index & Evaluation criteria \\
\hline \multirow{3}{*}{$\begin{array}{l}\text { Product utility value } \\
\text { assessment }\end{array}$} & $\begin{array}{l}\text { Reduced cost of } \\
\text { investigation }\end{array}$ & $\begin{array}{c}0-10,0 \text { means that the investigation cost cannot be reduced at all, and } 10 \text { means } \\
\text { that the investigation cost can be greatly reduced }\end{array}$ \\
\hline & Reduced management cost & $\begin{array}{c}0-10,0 \text { means no management cost at all, } 10 \text { means significant reduction of } \\
\text { management cost }\end{array}$ \\
\hline & $\begin{array}{l}\text { Nonperforming loan risk } \\
\text { reduction }\end{array}$ & $\begin{array}{c}0-10 \text {, where } 0 \text { means no reduction of NPL risk at all, and } 10 \text { means significant } \\
\text { reduction of NPL risk }\end{array}$ \\
\hline
\end{tabular}

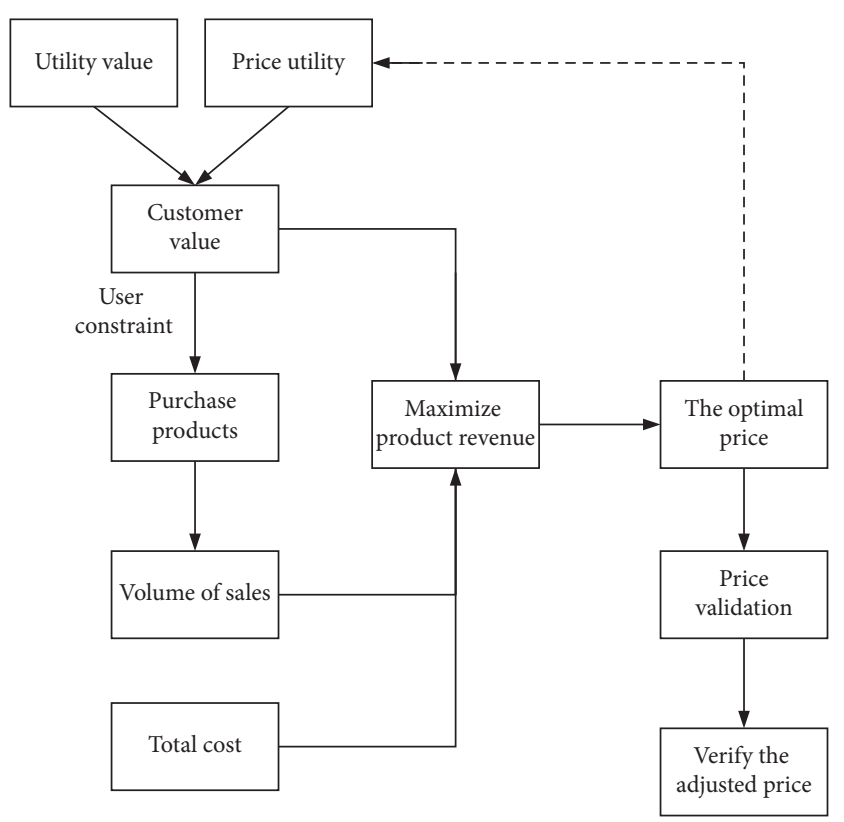

FIgURE 1: Revenue maximization pricing process.

(i) $K$ : the fixed cost of the electricity credit product, which is a constant

(ii) $c$ : the unit variable cost of a power system product, which is a constant

(iii) $Q_{0}$ : the estimated amount of electricity and product usage, which is a constant

(iv) $\pi_{S G C}$ : revenue from electric power credit products

The State Grid Corporation decides the price, and the profit maximization model is as follows:

$$
\begin{aligned}
\operatorname{Max} \pi_{S G C} & =Q_{0} p-K-c Q_{0}, \\
\text { s.t. } & \mathrm{E}[V]=\sum_{i=1}^{n} u\left(g_{i}\right)+\alpha+\gamma p \geq 0, \\
Q_{0} p-K-c Q_{0} & \geq 0 .
\end{aligned}
$$

Objective function $\pi_{S G C}(p)$ indicates that the enterprise formulates the product as $p$. The first constraint means that the firm will buy products only if the customer value of a single product is not less than zero, and the second constraint means that the expected revenue from the selling products is not less than the cost of investment.
Solve the first constraint to get $p \leq-1 / \gamma\left(\sum_{i=1}^{n} u\right.$ $\left.\left(g_{i}\right)+\alpha\right)$. Therefore, it is known that $-1 / \gamma\left(\sum_{i=1}^{n} u\left(g_{i}\right)+\alpha\right)$ is a price cap constraint.

Solve the second constraint to get $p \geq K / Q_{0}+c$. Therefore, it is known that $K / Q_{0}+c$ is a break-even price of expected sales volume and a price floor constraint.

When $\left.K / Q_{0}+c\right\rangle-1 / \gamma\left(\sum_{i=1}^{n} u\left(g_{i}\right)+\alpha\right)$, the price domain is an empty set, and the price $p$ has no solution.

When $K / Q_{0}+c \leq-1 / \gamma\left(\sum_{i=1}^{n} u\left(g_{i}\right)+\alpha\right)$, the domain of the price is $p \in\left[K / Q_{0}+c,-1 / \gamma\left(\sum_{i=1}^{n} u\left(g_{i}\right)+\alpha\right)\right]$. Price $p$ is in this domain.

Taking the derivative of the total revenue of the state grid enterprise, we get the following:

$$
\pi_{S G C}^{\prime}(p)=Q_{0} \geq 0 .
$$

$\pi_{S G C}(p)$ is monotonically increasing with respect to $p$, and hence, when $p=-1 / \gamma\left(\sum_{i=1}^{n} u\left(g_{i}\right)+\alpha\right)$, the maximum value of the total revenue of the state grid enterprise is $\pi_{S G C}\left(-1 / \gamma\left(\sum_{i=1}^{n} u\left(g_{i}\right)+\alpha\right)\right)$.

To sum up, when $K / Q_{0}+c \leq-1 / \gamma\left(\sum_{i=1}^{n} u\left(g_{i}\right)+\alpha\right)$, the optimal price of the State Grid is $p^{*}=-1 / \gamma\left(\sum_{i=1}^{n} u\left(g_{i}\right)+\alpha\right)$.

The research on the pricing decision of electric power credit products gives the price of a product, however, this price is mainly based on the subjective judgment of enterprises and needs to be further verified by pricing, i.e., to verify the rationality of pricing through market research. Pricing verification mainly uses pricing testing methods, such as price breaking point model (Gabor Granger) and price sensitivity meter (PSM), psychological price difference test, and brand price trade off (BPTO) test, to verify or test the price of the product.

The pricing model of the revenue maximization of electric power data credit products is mainly to find a reasonable pricing level without considering the market strategy and strategy of enterprises, including expanding market share aand improving corporate image. The price is aimed at maximizing the profits of enterprises, which may be inconsistent with the actual situation of enterprises. However, it can be used as a reference for enterprises to further formulate market strategies. When $K / Q_{0}+c \leq-1 / \gamma\left(\sum_{i=1}^{n} u\right.$ $\left.\left(g_{i}\right)+\alpha\right)$, the best price $p^{*}=-1 / \gamma\left(\sum_{i=1}^{n} u\left(g_{i}\right)+\alpha\right)$ is a ceiling price that can be used as a reference and adjusted according to the actual situation.

Referring to the prices of competing products in Table 2, since the highest price and the lowest price may cause extreme interference, the average value is calculated by removing one highest price and one lowest price, and the average value is 5.88 yuan/time. Because of the monopoly of 
TABLE 2: Expert assessment of average product utility value.

\begin{tabular}{|c|c|c|c|}
\hline & Evaluation index & $\begin{array}{l}\text { Evaluated } \\
\text { mean }\end{array}$ & Evaluation criteria \\
\hline \multirow{3}{*}{$\begin{array}{l}\text { Product utility value } \\
\text { assessment }\end{array}$} & $\begin{array}{l}\text { Reduced cost of } \\
\text { investigation }\end{array}$ & 7 & $\begin{array}{c}0-10,0 \text { means that the investigation cost cannot be reduced at all, and } 10 \\
\text { means that the investigation cost can be greatly reduced }\end{array}$ \\
\hline & $\begin{array}{l}\text { Reduced management } \\
\text { cost }\end{array}$ & 8 & $\begin{array}{c}0-10,0 \text { means no management cost at all, and } 10 \text { means significant } \\
\text { reduction of management cost }\end{array}$ \\
\hline & $\begin{array}{l}\text { Nonperforming loan risk } \\
\text { reduction }\end{array}$ & 5 & $\begin{array}{c}0-10 \text {, where } 0 \text { means no reduction of NPL risk at all, and } 10 \text { means } \\
\text { significant reduction of NPL risk }\end{array}$ \\
\hline
\end{tabular}

power data and the high relative value of power data credit products, the average price of bidding commodities is considered to be 5.88 yuan per time as the lower limit of the pricing range. However, because $K / Q_{0}+c$ is a break-even price of expected sales volume and a price floor constraint, when the break-even price of the estimated sales volume is not greater than the average price of the bidding commodity, i.e., when $K / Q_{0}+c \leq 5.88$, the average price of bidding commodities 5.88 yuan/time is a lower limit price for reference. When the break-even price of the estimated sales volume is greater than the average price of the bidding commodity, i.e., when $\left.K / Q_{0}+c\right\rangle 5.88$, the break-even price of the estimated sales volume $K / Q_{0}+c$ is a floor price for reference.

Based on the above analysis, the conclusion 1 is as follows:

Conclusion 1. when $K / Q_{0}+c \leq \min \left\{5.88,-1 / \gamma\left(\sum_{i=1}^{n} u\right.\right.$ $\left.\left.\left(g_{i}\right)+\alpha\right)\right\}$, the pricing range of the State Grid is $\left[5.88,-1 / \gamma\left(\sum_{i=1}^{n} u\left(g_{i}\right)+\alpha\right)\right] ; \quad$ when $5.88\left\langle K / Q_{0}+c \leq\right.$ $-1 / \gamma\left(\sum_{i=1}^{n} u\left(g_{i}\right)+\alpha\right)$, the pricing range of the State Grid is $\left[K / Q_{0}+c \leq-1 / \gamma\left(\sum_{i=1}^{n} u\left(g_{i}\right)+\alpha\right)\right]$.

\section{Numerical Analysis}

According to market research, the unit variable cost of financial risk control products of a company of State Grid $c$ is 1.60 yuan/time, and the cost is basically variable. Hence, it is assumed that the fixed cost $K$ is 0 . Taking the price of financial wind control products as an example, the following numerical analysis is made.

5.1. Determine the Utility Value of the User. The utility value is obtained according to the expert's evaluation of the utility value of the product. The average value of the utility value evaluated by the experts is the utility value of the product, as shown in Table 2 , and the average product utility value $U=$ 20 is evaluated by the experts.

5.2. Determine the Price of Competing Products. Make statistics on the prices of current market data products and prepare the price reference table of competing products, as shown in Table 3.

Because the highest price and the lowest price may cause extreme interference, the average value is calculated by removing one highest price and one lowest price, and the average value is 5.88 yuan/time. With reference to the prices of competing products in Table 2 and based on the utility of the price paid by financial institutions when they purchase and use financial risk control products, we have developed a product price utility evaluation table as follows.

5.3. Determine the Price Utility of the User. The price utility is obtained according to the expert's evaluation of the utility of the product price. The average value of the product price utility evaluated by the statistical experts are shown in Table 4 as follows.

According to the expert's evaluation of product price utility, the price index and evaluation score are taken as samples to meet the following requirements: $u_{p_{j}}=\alpha+\gamma p_{j}+\varepsilon$. Use the method of unary linear regression analysis to estimate the parameters of $\alpha$ and $\gamma$, and the test results are shown in Figure 2 as follows:

As $R^{2}=0.9437$, it shows that there is a strong linear correlation between price and price utility, which indicates that the regression model is effective. Hence, the correlation coefficient of price utility $\alpha=0.8105$ and $\gamma=-1.8248$.

5.4. Determine the Customer Value of Users. Customer value includes utility value and price utility relationship, which is expressed as follows:

$$
\begin{aligned}
V & =\sum_{i=1}^{n} u\left(g_{i}\right)+\alpha+\gamma p+\varepsilon \\
& =20.8105-1.8248 p+\varepsilon .
\end{aligned}
$$

5.5. The Optimal Price of the State Grid. Upon substituting the determined utility value $U=20$ and the correlation coefficient $\alpha=0.8105$ and $\gamma=-1.8248$ of the determined price utility into the ceiling price, we get,

$p^{*}=-\frac{1}{\gamma}\left(\sum_{i=1}^{n} u\left(g_{i}\right)+\alpha\right)=-\frac{1}{-1.8248}(20+0.8105) \approx 11.40$.

Because of $K / Q_{0}+c=1.6 \leq 5.88$ and $K / Q_{0}+c=1.6 \leq$ $-1 / \gamma\left(\sum_{i=1}^{n} u\left(g_{i}\right)+\alpha\right) \approx 11.4$, the pricing range of financial risk control products is 5.88 yuan/time-11.40 yuan/time.

The rationality of pricing is further verified by market research, which mainly uses pricing testing methods, such as price breaking point model (Gabor Granger), price 
TABle 3: Price reference table of competitive products.

\begin{tabular}{|c|c|c|c|}
\hline Product name & $\begin{array}{l}\text { Charging } \\
\text { method }\end{array}$ & $\begin{array}{c}\text { Price } \\
\text { (yuan/time) }\end{array}$ & Remark \\
\hline Tax & $\begin{array}{l}\text { Query-by- } \\
\text { time }\end{array}$ & 100 & 皮 \\
\hline Enterprise justice & $\begin{array}{l}\text { Query-by- } \\
\text { time }\end{array}$ & 4 & $\begin{array}{c}0-100,000 \text { pieces/ } 4 \text { yuan/piece; } 100,000-50,000 \text { pieces } / 3.5 \text { yuan/ } \\
\text { piece; } 500,000-900,000 / 3 / \text {; cap price of more than } 900,000 \\
\text { pieces: } 2 \text { million/year }\end{array}$ \\
\hline Telecommunications & $\begin{array}{l}\text { Query-by- } \\
\text { time }\end{array}$ & 6 & 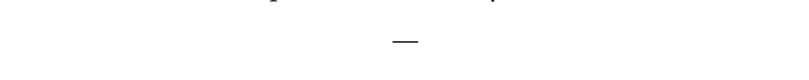 \\
\hline Credit & $\begin{array}{l}\text { Query-by- } \\
\text { time }\end{array}$ & 5 & - \\
\hline $\begin{array}{l}\text { Basic information of industry and } \\
\text { commerce }\end{array}$ & $\begin{array}{l}\text { Query-by- } \\
\text { time }\end{array}$ & 29.05 & - \\
\hline $\begin{array}{l}\text { Industrial and commercial intellectual } \\
\text { property }\end{array}$ & $\begin{array}{l}\text { Query-by- } \\
\text { time }\end{array}$ & 1.7 & - \\
\hline $\begin{array}{l}\text { Industrial and commercial association } \\
\text { map }\end{array}$ & $\begin{array}{l}\text { Query-by- } \\
\text { time }\end{array}$ & 1 & - \\
\hline $\begin{array}{l}\text { Status of industrial and commercial } \\
\text { operation }\end{array}$ & $\begin{array}{l}\text { Query-by- } \\
\text { time }\end{array}$ & 2.1 & - \\
\hline Industrial and commercial operation risk & $\begin{array}{l}\text { Query-by- } \\
\text { time }\end{array}$ & 3.55 & - \\
\hline $\begin{array}{l}\text { Industrial and commercial directors, } \\
\text { supervisors and senior management }\end{array}$ & $\begin{array}{l}\text { Query-by- } \\
\text { time }\end{array}$ & 2.3 & - \\
\hline Tencent credit & $\begin{array}{l}\text { Query-by- } \\
\text { time }\end{array}$ & 5 & $5-6 /$ Bar \\
\hline Sesame credit & $\begin{array}{l}\text { Query-by- } \\
\text { time }\end{array}$ & 5 & $5-6 / \mathrm{Bar}$ \\
\hline Logistics distribution data & $\begin{array}{l}\text { Query-by- } \\
\text { time }\end{array}$ & 0.5 & - \\
\hline Average price & $\begin{array}{l}\text { Query-by- } \\
\text { time }\end{array}$ & 5.88 & Average after removing the highest and lowest prices \\
\hline
\end{tabular}

TABLe 4: Average product price utility evaluated by the experts.

\begin{tabular}{|c|c|c|c|}
\hline & $\begin{array}{l}\text { Price index } \\
\text { (yuan) }\end{array}$ & $\begin{array}{l}\text { Evaluation } \\
\text { score }\end{array}$ & Evaluation standard \\
\hline $\begin{array}{l}\text { Product price utility } \\
\text { evaluation }\end{array}$ & $\begin{array}{c}1 \\
2 \\
3 \\
4 \\
5 \\
6 \\
7 \\
8 \\
9 \\
10 \\
11 \\
12 \\
13 \\
14 \\
15 \\
16 \\
17 \\
18 \\
19 \\
20\end{array}$ & $\begin{array}{c}0 \\
-2 \\
-3 \\
-5 \\
-6 \\
-8 \\
-12 \\
-15 \\
-18 \\
-20 \\
-21 \\
-22 \\
-25 \\
-30 \\
-30 \\
-30 \\
-30 \\
-30 \\
-30 \\
-30\end{array}$ & $\begin{array}{l}-30-0 \text { means the degree of acceptance when the price is set, }-30 \text { means that the } \\
\text { price is completely unacceptable, at this time the price utility is the smallest, } 0 \\
\text { means it is completely acceptable, and the price utility can be ignored at this time }\end{array}$ \\
\hline
\end{tabular}




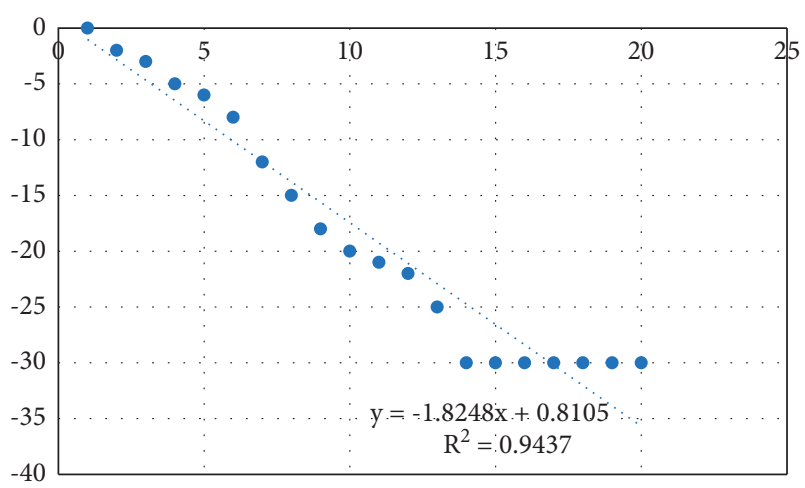

FIgURE 2: Unary linear regression.

sensitivity meter (PSM), psychological price difference test, and brand price trade off (BPTO) test, to verify or test the price of the product. After the market runs, the interval price will be further adjusted according to the market reaction.

\section{Conclusion}

Firstly, according to the effectiveness of financial institutions in purchasing and using financial risk control products, the benefit evaluation index of power data credit products is formulated. Secondly, the benefit evaluation model of electric power data credit products is constructed to determine the user's utility value and price utility, respectively, to determine the customer value. Then, based on the benefit evaluation model, by maximizing the product revenue, to find a balance between user constraints and the company's interests, the State Grid Corporation formulates the optimal pricing strategy. Finally, the numerical analysis formulates the price strategy of financial wind control products. This paper gives the pricing strategy of electricity credit, which can be used as a reference for enterprises to further formulate market strategies.

\section{Data Availability}

The competitor product data in the article mainly comes from the public quotations of credit reporting companies' products.

\section{Conflicts of Interest}

The authors declare that they have no conflicts of interest.

\section{Acknowledgments}

Supporting Project No: Science and Technology Project of State Grid Corporation of China (1400-202057219 A-0-0$00)$.

\section{References}

[1] China Academy of Information and Communications Technology, Big Data White Paper, China Academy of Information and Communications Technology, Beijing, China, 2016.
[2] Z. Wu, "Improvements to the pricing of credit data of China's credit information center," Economist, no. 8, pp. 96-98, 2017.

[3] H. Koski, Does Marginal Cost Pricing of Public Sector Information spur Firm Growth?, The Research Institute of the Finnish Economy (ETLA), Helsinki, Finland, 2011.

[4] L. Olejnik, T. Minh-Dung, and C. Castelluccia, "Selling off privacy at auction," HAL-Inria, vol. 37, no. 12, p. 54, 2013.

[5] Z. Zhang, D. Yang, and H. Wu, "Research and application of data asset value evaluation model," Modern Electronic Technology, vol. 38, no. 20, p. 44, 2015.

[6] P. Koutris, P. Upadhyaya, M. Balazinska, and B. Howe, "Toward practical query pricing with Query Market," in Proceedings of the 2013 ACM SIGMOD International Conference on Management of Data, p. 613, Newyork, NY, USA, 2013.

[7] B.-R. Lin and D. Kifer, "On arbitrage-free pricing for general data queries," Proceedings of the VLDB Endowment, vol. 7, no. 9, pp. 757-768, 2014.

[8] C. Riederer, V. Erramilli, A. Chaintreau, B. Krishnamurthy, and V. Erramilli, "For sale: your data: by you," in Proceedings of the ACM workshop on hot topics in networks, Cambridge, MC, USA, November 2011.

[9] P. Dandekar, N. Fawaz, and S. Ioannidis, "Privacy auctions for inner product disclosures," Co R R, abs/1111, vol. 2885, no. 9, p. 35, 2011.

[10] C. Li, D. Y. Li, G. Miklau, and D. Suciu, "A theory of pricing private data," ACM Transactions on Database Systems, vol. 39, no. 4, p. 34, 2012.

[11] A. Rosenthal, Take it or Leave it: Running a Survey when Privacy Comes at a Cost, p. 378, Springer Press, Heidelberg, 2012.

[12] A. Ghosh and A. Roth, "Selling privacy at auction," Games and Economic Behavior, vol. 91, no. 91, pp. 334-346, 2015.

[13] N. Jentzsch, "Auctioning privacy-sensitive goods:," Privacy Technologies and Policy, vol. 87, no. 23, pp. 133-142, 2014.

[14] L. Zhai, Z. Ma, and S. Zhang, "A review of research on the pricing of big data products," Technology and Management, vol. 20, no. 6, pp. 109-114, 2018.

[15] H. Li, Research on the Pricing of Telecommunication Information Products Based on Customer Value, Beijing University of Posts and Telecommunications, Beijing, China, 2009.

[16] R. Liu, Research on Book Pricing Method Based on Customer Perceived Value, Dalian University of Technology, Dalian, China, 2006.

[17] S. Fosu, A. Danso, H. Agyei-Boapeah, and C. G. Ntimau, "Credit information sharing and bank loan pricing: do concentration and governance matter?" International Journal of Finance \& Economics, vol. 26, no. 4, pp. 5884-5911, 2021. 